\title{
Virtual player profile associated with personal motivation to play in CityVille
}

\section{Perfil de jugador virtual asociado a la motivación personal para jugar en CityVille}

\author{
$\mathrm{M}^{\mathrm{a}}$ Esther del Moral-Pérez \\ Universidad de Oviedo. Oviedo, España \\ emoral@uniovi.es \\ Alba Patricia Guzmán-Duque \\ Unidades Tecnológicas de Santander. Santander, Colombia \\ aguzman@correo.uts.edu.co
}

\begin{abstract}
This research describes the Community Fans-Cityville $(\mathrm{N}=110)$ depending on the variables sex, time dedicated to the game, level reached and money invested. It also identifies the three player profiles associated with the given motivations to remain in the game, the prioritized objectives in the game and the alleged reasons to interact with other players: a) utilitarian-addictive, b) recreational-collaborative learning, and c) prosocial. Among the results it is observed that the players have fun interacting online and collaborating with others to grow their cities, they are happy playing and sharing hobby. Almost half play between 3-6 hours a day in CityVille and, although you could play without spending money, almost half spend an average of $\$ 8$ monthly to advance faster. Men are more utilitarian, seek to reach the highest level and only interact with others to gain and win; Unlike women who prioritize collaborative and prosocial entertainment, they value the exchange of strategies, mutual collaboration and the opportunity that the game offers to broaden their network of contacts and friendships.
\end{abstract}

\section{Key words}

CityVille, Social Network Games, Personal Motivation, Player profile

\section{Resumen}

Esta investigación describe la comunidad Fans-CityVille $(\mathrm{N}=110)$ en función de las variables sexo, tiempo dedicado al juego, nivel alcanzado y dinero invertido. Asimismo, identifica los tres perfiles de jugador virtual asociados con las motivaciones esgrimidas para permanecer en el juego, los objetivos priorizados en el mismo y las razones alegadas para interactuar con otros jugadores: a) utilitarista-adictivo, b) aprendizaje lúdico-colaborativo, y c) prosocial. Entre los resultados se observa que los usuarios juegan para divertirse interaccionando online y colaborando con otros para hacer crecer sus ciudades en CityVille, son felices jugando y compartiendo afición. Aproximadamente la mitad juega entre 3-6 horas diarias y, aunque se podía jugar sin gastar dinero, casi la mitad invertía una media de 8 mensuales para avanzar más rápido. Los hombres se muestran más utilitaristas, buscan alcanzar el máximo nivel y solo interactúan con otros jugadores para obtener beneficios y ganar; a diferencia de las mujeres que valoran el aprendizaje derivado de este entretenimiento colaborativo y prosocial, ponderan más el intercambio de estrategias, la colaboración mutua y la oportunidad que les brinda el juego para ampliar su red de contactos y amistades.

\section{Palabras clave}

CityVille, juegos en red social, motivación personal, perfil de jugador. 


\section{Introduction}

Multiplayer gaming has become widespread on social networks, especially so through connections on Facebook, making the relationships between users more dynamic, favoring their intercommunication within the fun activities of various types to which they have subscribed, promoting a collaborative type of entertainment and encouraging player interaction (Burroughs, 2014), and facilitating knowledge transmission among those users who converge on these ludic spaces around pre-established play parameters (Camilleri, Busuttil \& Montebello, 2011).

The online gaming phenomenon spreads virally thanks to users' connections on networks (Facebook, Tuenti, Google+, etc.), making it possible for people from all over the world to communicate with one another and strike up relationships in order to take part in a wide variety of tournaments and games, combats and bloody fights to death which end up trivializing wars (Gagnon, 2010). Or in role play games where each person assumes different roles, acquiring skills through training (Granic, Lobel \& Engels, 2014). Or even in other more elaborate games of a prosocial nature focused on building farms, cities, or castles, amongst other things, which encourage not only collaboration but also the transfer of strategies or knowledge linked to demands and developments which are specific to each game (Camilleri, Busuttil \& Montebello, 2011). A number of studies have analyzed the cognitive influence exerted by such virtual scenarios, both in positive terms (Chiang, Lin, Cheng \& Liu, 2011) and from a negative perspective associated with the risk that they entail when it comes to strengthening sexist stereotypes (Smith \& Moyer-Gusé, 2005) or favoring racist attitudes (De Vane \& Squire, 2008) or because they recreate excessively violent and destructive war contexts (Carnagey, Anderson \& Bushman, 2007). Others have as their main aim to examine the opportunities offered by some videogames when it comes to learning social values and counter-values (Greitemeyer \& Osswald, 2010).

The present study stems from our verification that these appealing scenarios have exceeded all expectations, exponentially increasing the number of users and generating a new game play culture (Shaw, 2010). Without a doubt, social networks along with other mobile applications are the main driving forces behind this revolution which can promote permanent interaction practices, leading some Internet companies to use micro-games with the aim of attracting more customers towards their platforms and exploiting the business opportunities generated by their interconnection (De Andrade, 2012; Feinleib, 2011).

The key to the success achieved by networked gaming lies in its capacity to summon multiple users, breaking barriers and modeling interests. On the basis of the social network theory and the analysis of the social structures from interactions, Choi, Choi and Song (2012) explain that human behavior may be influenced -reasons, objectives and priorities to communicate- in these ludic relational contexts, due to factors such as constant interaction and the type of play themes and mechanics, which in turn is likely to affect their wishes, feelings and ways to act. Nevertheless, although there are actually war-related games which bring many players together and mainly seek the destruction and almost apocalyptic annihilation of individuals and cities, thus provoking violent attitudes and behaviors (Delisi, Vaughn, Gentile, Anderson \& Shook, 2013), this paper has as its purpose to give continuity to the work carried out by Cole and Griffiths (2007), analyzing how the social interaction derived from shared play in networks can favor collaborative construction as well as the development of social skills.

The awareness that these games boost some peculiar social interaction dynamics and favor a collaborative type of entertainment led us to approach the study from a constructive, prosocial perspective following Tear and Nielsen (2013), leaving aside the

Virtual player profile associated with personal motivation to play in CityVille. M. Esther del Moral Pérez y Alba Patricia Guzmán Duque.

Página 2 de 18 
war games oriented to promote fighting and shooting strategies, which can unconsciously result in undesirable conduct patterns (Whitaker \& Bushman, 2012).

Based on our conviction that collaborative play provides chances for highly advantageous socio-cognitive learning, the game CityVille was selected with the aim of verifying whether or not it facilitates collaboration and strategy exchange between players for the construction of virtual cities. Therefore, the first step consists in describing game design as a critical factor which helps users stay in the game and favors their interactions, after which a survey among users will permit to analyze their reasons and objectives to play, as well as the priorities that they establish when it comes to communicating with their game neighbors.

\section{The enhanced social interaction generated by games played on social networks}

For Taylor (2009), networked games have a design which captivates users, ensures their continuance and favors their mutual interaction and socialization, helping them live enriching play experiences (Corliss, 2011). They are usually intuitive, with easy-tounderstand mechanisms that include surprises meant to activate players' motivation, attention and concentration; they present players with attractive tasks and challenges through which they can reach a personal improvement, progressively increasing the level of difficulty, avoiding boredom and maintaining those players' degree of satisfaction with their achievements (Desurvire \& Wiberg, 2009). Most of them include systems to reward both continuance in the game and perseverance when performing tasks until they are completed. Their aim is to make players have the perception that they always move forward and are free to decide the amount of time spent in the game without any penalties, suggesting accessible goals and innovative challenges to guarantee that players will remain active in the game.

The context and dynamics of a game often provokes the immersion or flow effect, making players become involved and integrated into these virtual worlds (Cowley, Charles, Black \& Hickey, 2008). They ensure usability in interfaces which recreate fantastic worlds (Jørgensen, 2012); according to Weibel, Wissmath, Habegger, Steiner and Groner (2008), the mere presence and immersion of any player in such environments generates satisfaction in them, since they take part in the missions proposed feeling that they are active protagonists. Furthermore, these types of games seek to provoke emotional responses to the stimuli presented in order to achieve an even higher degree of involvement, which they do through the incorporation of attributes that reinforce personal identity with avatars, and showing the scores obtained by players so that comparisons can be drawn, etc.

To all of the above must be added that the social interaction promoted by games played on social networks not only contributes to increase the social capital which converges on them -as it happened in Massive Multiplayer Online Games (MMOGs), regarded as their forerunners- but also brings about a wide variety of changes in subjects' behaviors. Liu and Peng (2009) conclude that a large number of users have actually adapted their lives to these ludic formulas and now prefer online social interaction, linking such attitudes with a psychological dependence on the game. Kim, Namkoong, Ku and Kim (2008), Lo, Wang and Fang (2005), and, Wang and Chiou (2006) claim that these networked games are likely to provoke addiction, whereas Caplan, Williams and Yee (2009), Chiang, Lin, Cheng and Liu (2011), Cole and Griffiths (2007), and, Ducheneaut, Moore and Nickell (2007) assess the positive social phenomena generated within these multiplayer online games, among which stands out the encouragement of collaborative interactions through the creation of communities closely associated with virtual games.

Virtual player profile associated with personal motivation to play in CityVille. M. Esther del Moral Pérez y Alba Patricia Guzmán Duque.

Página 3 de 18 
Jeon (2001) points out that these ludic platforms are massively used because of the interest and flexibility that they offer as far as communication is concerned. Williams, Kennedy and Moore (2011) define them as creative formulas for socialization, insofar as their connectivity allows many subjects to improve their confidence and social acceptance levels. They help in the acquisition of numerous cognitive capabilities and skills (Connolly, Boyle, MacArthur, Hainey \& Boyle, 2012; Ducheneaut \& Moore, 2005); they favor manifold types of learning derived from decision-making and problemsolving mechanisms applied to situations arising in the game (Hou, 2012); and they also give rise to substantial changes in social learning (Paraskeva, Mysirlaki \& Papagianni, 2010), generating ties between those players who are united by their common interests (Choi, Choi \& Song, 2012).

More precisely, CityVille boosts compulsory interconnection practices meant to prevent energy loss, 'death' or total disappearance -a recurrent factor, as was highlighted by Van Meurs (2011). Hence the spontaneous appearance of virtual videogamer communities which, due to their specific characteristics, become optimal scenarios for strategy and knowledge transfer, since they generate some types of learning based on mutual collaboration which are mainly oriented towards problem solving or focused on the completion of the missions proposed by this videogame.

The aforesaid virtual videogamer communities appear as peculiar spaces where it is possible to connect with other users, and where the game creates relationships which often generate a strong feeling of interdependence that can ultimately give rise to enriching experiences for everyone (Burroughs, 2014), materialized in the achievements established in each game (Hussain \& Griffiths, 2009) or, like in CityVille, in social recognition, the appointment as mayor or governor..., all of which contributes to increase the player's reputation and popularity (Kowert \& Oldmeadow, 2013).

The relevance of these communities lies in the opportunities that they offer for players to optimize their strategies by sharing them with others, consequently giving added value to the decision making or problem solving mechanisms put into practice before the situations which might eventually arise, and activating connective intelligence (Siemens, 2008). For this reason, some communities are organized around forums, either official ones created by the actual game in order to provide support to players; or others which constitute an initiative undertaken by certain users as a way to channel the exchange of experiences, tricks and useful advice to move forward, to improve the degree of interaction between players and even to make friends. That is what happens in CityVille, where the aim basically focuses on the construction of a city taking advantage of the help and resources provided by other neighbors or inhabitants connected on social networks and organized around different forums.

\section{CityVille: a constructive, socializing simulation game}

Companies like Zynga -created by Mark Pincus in 2007 and closed from April 2015developed constructive ludic applications in the style of CityVille, Draw Something, FarmVille, CastleVille, Empires \& Allies, CafeWorld, Indiana Jones, Adventure World, etc., which bring together ca. 240 million players from 175 nationalities. More precisely, the present study is centered on analyzing the CityVille phenomenon -after its 2010 release on Facebook - for being available in Spanish, English, French, German and Japanese and for having over 17 million users worldwide (Zynga, 2013).

CityVille is supported on simulation as a strategy for construction, and it has the capacity to generate very diverse types of learning (Nummenmaa, Alha \& Kultima, 2011). It proposes the creation of virtual cities through the construction of houses, businesses, community or government buildings..., and considering the increase in the number of inhabitants a key factor to move up levels. It is conceived to establish collaboration relationships between players and also fosters the acknowledgment of

Virtual player profile associated with personal motivation to play in CityVille. M. Esther del Moral Pérez y Alba Patricia Guzmán Duque.

Página 4 de 18 
other people's experience by rewarding visits to their neighbors' cities (Jeon, 2001). It additionally offers different options for socialization: a) it encourages users to invite their acquaintances to play, thus turning them into their neighbors; and b) it promotes relationships with new players. Both options increase contact with new neighbors, thanks to which money and energy collection levels grow, which logically contributes to make their city bigger (Kincaid, 2010). Wohn, Lampe, Wash, Ellison and Vitak (2011) remark that interpersonal reasons are the main driving force behind this game and, although they do not promote direct social interaction, participants perceive it from the shared utilization of game resources and contents, which is why they recommend maintaining -and even strengthening- these relationships.

The design of CityVille is simple; it has a graphical interface with dropdown menus and intuitive icons appealing to well-known metaphors that contribute to give verisimilitude to the game scenario, making navigation and interaction easier within the ludic environment, in accordance with the usability and playability criteria defined by Desurvire and Wiberg (2009). Its graphical interface provides players with different options by means of windows and intuitive icons which identify the data corresponding to their city along with the level reached through 'XP' collection (Figure 1 shows the city of a level-91 player). A display shows the energy, coins and products that the player has, as well as the availability of CityCash or game money and, finally, the resources accumulated to improve the city, and also to extend its population and surface area, together with the product stock. The game shows the rewarded tasks and makes proposals for new missions that supply additional energy, new permits to expand, coins and pay missions, generating new challenges to move up levels.

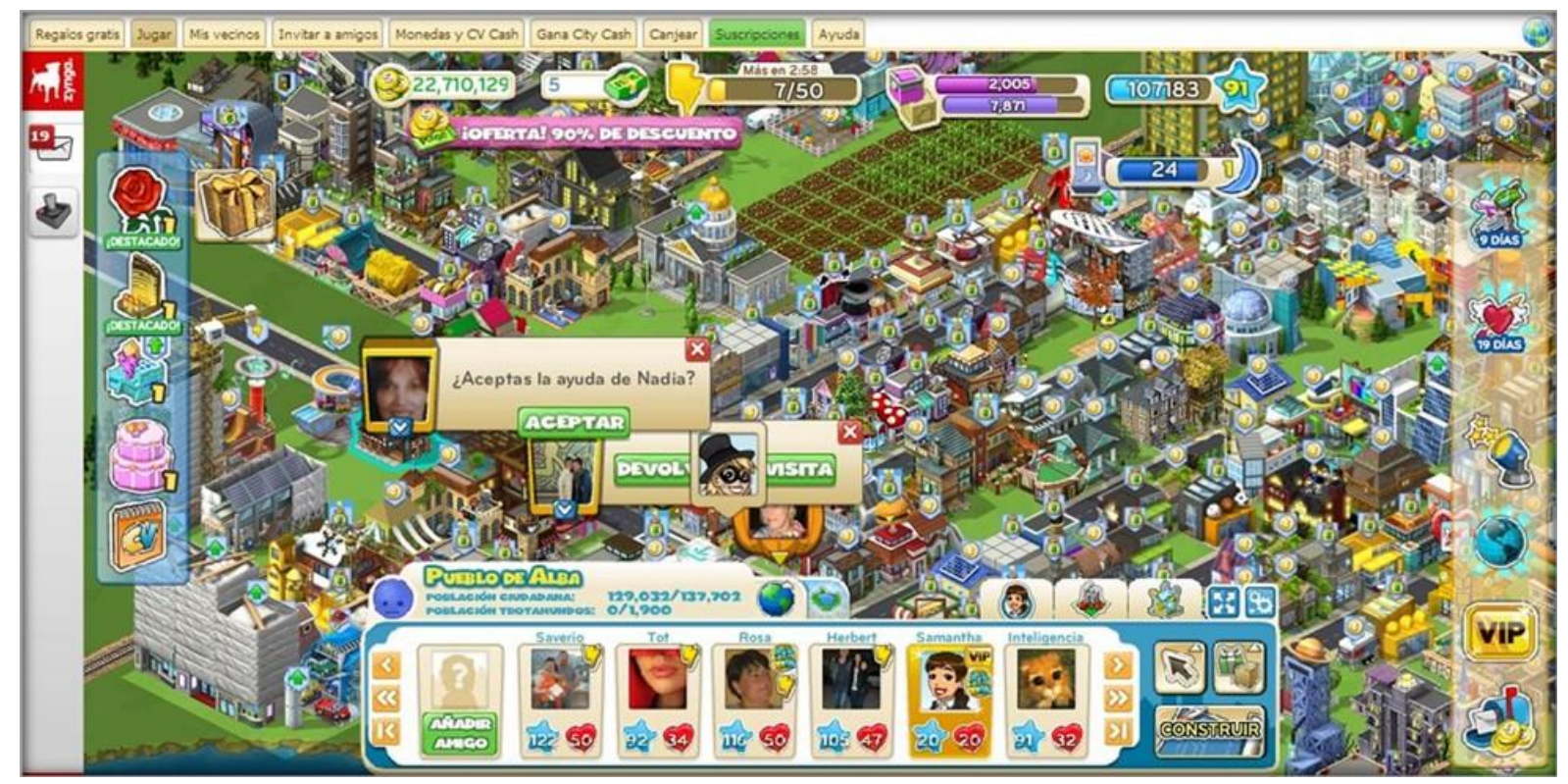

Figure 1. CityVille graphical interface

The game permanently encourages socialization between players insisting not only on the invitation to friends from the social network but also on the access to neighbors' cities to offer them gifts. Their mutual interaction is also made visible, identifying those who visit the city with the expectation that their visit will be returned and that they will be rewarded for it, showing their scores and thus favoring competitiveness. The game is governed by rules which regulate players' progress, and it also promotes selfdevelopment and coping -valued with a promotion to the next level. Promotion becomes more demanding as the game moves forward, requiring a higher degree of

Virtual player profile associated with personal motivation to play in CityVille. M. Esther del Moral Pérez y Alba Patricia Guzmán Duque.

Página 5 de 18 
participation and activity on the part of players in order to reach higher levels (Ducheneaut, Yee \& Nickell, 2006).

There are rules for the construction of a virtual city which include reward formulas meant to ensure continuance in the game, and mechanisms to activate interaction and collaboration between neighbors, including: promotion to the next level; and increasing the number of inhabitants. Going up levels requires dedication and time to construct community buildings and multiply the population, which in turn permits to obtain extra energy to enlarge the virtual estate. Promotion to a higher level is associated with a population increase. A number of dwellers is allocated to each built house (from 10 to 1,000 or more), the same as to community buildings (between 50 and 2,500) -always depending on the player's level. As the population grows, the city becomes larger and has more services (e.g. cafés, hotels, banks or leisure areas) and that makes it possible to go up levels, obtaining more energy or CityVille money, which reinforces the interest of players in prospering- as this will allow them to carry out more actions.

The reward formulas in CityVille contribute to increase extrinsic motivation and also to encourage the continuance in the game of online users through the collection of 'XP' energy, coins, gifts for the time that they spend in their virtual city, and for visits to neighbors or to the official forum. Challenges are also proposed for players to extend their stay in the game, suggesting new rewarded missions, making it possible to enlarge the city with commercial or industrial districts, or nightlife areas, amongst other things, appealing to a nominal recognition which increases their prestige as players through an appointment as mayors, governors, etc. Table 1 provides a summary of the actions rewarded by the game as well as of those which require an investment or payment (energy or coins) so that their virtual city can grow, something that is promoted through:

- Continuance in the game: connection time and energy generation

- Promotion to the next level: moving up levels, expansion of the city and increased number of dwellers and construction of shopping malls and playgrounds

- Interaction and collaboration with neighbors: visits to neighbors, irrigation or recovery of crops, delivery of gifts and answers to neighbors' requests, creation of franchises, and ship cleaning

- Money collection: product sales, building and house rentals, field harvesting and visits to shopping malls

- Commercialization: supply to businesses and investment in decoration items

Table 1. Rewarded and pay actions in CityVille. Elaborated by the authors.

\begin{tabular}{|c|c|c|c|c|}
\hline Game actions & Energy & $\mathbf{X P *}$ & Coins & Restrictions \\
\hline $\begin{array}{l}\text { 1) Continuance in the } \\
\text { game }\end{array}$ & $R: 1-50$ & & & It always generates profits \\
\hline 2) Moving up a level & $\begin{array}{c}\text { R: } 30-50 \\
\text { E/P-R: } 1-12\end{array}$ & $R: 1-10$ & $\begin{array}{l}\text { R-E/P: } \\
1,000 \ldots\end{array}$ & $\begin{array}{l}\text { Difficulty increases as players } \\
\text { move forward in the game }\end{array}$ \\
\hline $\begin{array}{l}\text { 3) Interaction and } \\
\text { collaboration with } \\
\text { neighbors: }\end{array}$ & $\mathrm{R}: 1-10$ & $\mathrm{R}: 1-10$ & $\begin{array}{c}\text { R: } 125 \ldots \\
\text { R-E/P: } 25 \\
\ldots\end{array}$ & It is always rewarded \\
\hline 4) Money collection & $\mathrm{E} / \mathrm{P}: 1-5$ & $\mathrm{R}: 1-10$ & $\mathrm{R}: 25 \ldots$ & $\begin{array}{l}\text { There are always gains, never } \\
\text { losses }\end{array}$ \\
\hline 5) Commercialization & $E / P: 1-5$ & & E/P: $15-75$ & It always generates gains \\
\hline 6) Others... & $\mathrm{R}: 1$ & & R-E/P: 25 & It depends on the energy level \\
\hline
\end{tabular}

Virtual player profile associated with personal motivation to play in CityVille. M. Esther del Moral Pérez y Alba Patricia Guzmán Duque.

Página 6 de 18 
R: Revenue; E/P: Expense/Payment. Both in units. (...): It is the minimum revenue or expense/payment level; the maximum value depends on the level and number of virtual city dwellers.

${ }^{*} X P$ : points generated which reflect the level reached in the game

Similarly, interaction and collaboration between players are rewarded and proposed from:

- The promotion of visits to neighbors which, despite not being obligatory, bring material advantages (gifts to build new houses, community buildings and decorations; energy increases, or achievement of permits to expand the city, etc.). The game additionally offers them the chance to learn from the design and organizational strategies used by other players.

- The publication of requests on their personal profile or wall (permits and items or tools needed for building, energy...) addressed to their neighbors; they can offer to be hired to perform some task too or to work as employees at a community building, both parties winning with the barter of resources or services.

- Direct requests for help to neighbors by means of internal petitions sent to their user accounts -previously authorized in the game by the player (requests for gifts, energy, permits...).

- Online conversations between players via chat on Facebook, Google+... (direct requests for help, calls and invitations to carry out missions, according to each player's interests, etc.).

There is a system for reciprocal reward which helps acquire gifts for the actual city and favor the donation of items that the inhabitants may eventually need. CityVille has an official forum in English -with contributions in Spanish and Japanese- where users can share experiences, strategies and/or pieces of advice related to the expansion of their cities -which the game rewards every time the city is visited.

Furthermore, and even though users can play without spending their own money, they are encouraged -both inside the game and via Facebook- to buy CityCash with which players can obtain energy, products, permits or items needed to expand the city, increase its population and move up levels faster. This can mean a fixed economic investment assigned to the game.

\section{Methodology}

\section{Research context and aims}

The present study has as its purpose to verify whether or not the non-war constructive game developed in CityVille contributes to facilitate collaboration and strategy exchange, to identify the profile of CityVille players through the identification of the reasons which, in their opinion, lead them to play; the aims that they set themselves with the game and the priorities that they establish to communicate with their neighbors. Information was collected to that end with an online survey questionnaire administered to members of the case Fans-CityVille player community case $(\mathrm{N}=110)$ which was voluntarily responded by 105 subjects. The methodological procedure followed the criteria established by Wohn et al. (2011) when it comes to collecting information about the relationships generated between networked players.

\section{Instrument}

Virtual player profile associated with personal motivation to play in CityVille. M. Esther del Moral Pérez y Alba Patricia Guzmán Duque.

Página 7 de 18 
A CityVille user account served to invite active players to join an open community on Facebook and to answer a questionnaire which contained 12 items, 9 of them referring to their condition as online players and, more specifically, as CityVille players: their playing frequency; how and when they knew about the game; time dedicated to play every day; level reached; number of inhabitants who live in their virtual cities; number of neighbors that they have; and monthly economic investment made in the game. Together with 3 other items about more specific issues which showed their level of agreement -on a 1-to-5 Likert scale- with various statements referring to: a) their reasons to play in CityVille; b) their aims fixed with the game; and c) the priorities established to communicate with their neighbors in the game. In addition, to validate the questionnaire, it asked to ten players that respond the survey posted on Facebook.

\section{Procedure}

It started with the presentation of the descriptive data corresponding to the sample of players involved in the study. Then, after the application of multivariate statistical techniques such as bivariate correlation and Kendall's Tau-b statistic, an analysis was performed among variables of a nominal nature; and, finally, multiple regression served to show the relationships between variables -following Hair, Tatham, Anderson and Black (2010) and using SPSS (v. 18).

\section{Participant sample}

The sample was formed by 105 players from several countries who were members of the Fans-CityVille community and voluntarily answered the questionnaire. $62.9 \%$ of them were men and the remaining $37.1 \%$ were women. As for their countries of origin, $33.3 \%$ were Colombians, $24.8 \%$ Italians, $12.4 \%$ Mexicans, $11.4 \%$ Spaniards, $4.8 \%$ Germans, $4.8 \%$ Canadians, 3.8\% US nationals, and $4.7 \%$ came from other countries such as Angola, Saudi Arabia, Austria, Brazil and Paraguay. In terms of age, only $1.0 \%$ are younger than $18 ; 7.6 \%$ have ages comprised between 18 and $25,22.9 \%$ are 26 -to35 years old; the largest age group -with $44.8 \%$ - is that of players with ages between 36 and 45; another $20.0 \%$ are 46-to-55-year-olds; and only $3.8 \%$ are older than 55 .

The sample was subsequently described according to the data which illustrate their condition as CityVille players:

a) Activity in CityVille. The respondents see themselves as active players: $16.2 \%$ are only registered on 1 game; $51.4 \%$ on $2-4$ games; $23.8 \%$ on $5-7$ games; $5.7 \%$ on 8 10 games, and $2.9 \%$ on more than 10 games. Almost all of them $(94.3 \%)$ claim to be regular players; only $5.7 \%$ declare that they play once a week.

b) Way to access the game. 93.3\% state that they were invited by acquaintances or friends from Facebook; a marginal percentage of $2.9 \%$ entered out of curiosity; and another $2.9 \%$ were induced to play by advertising. $1.0 \%$ referred to the invitation to relatives.

c) Months spent in the game. $44.8 \%$ have been playing for $13-18$ months, followed by $29.5 \%$ with a playing period between 6 and 12 months, $18.1 \%$ who have been playing for less than 6 months, and $7.6 \%$ whose playing period is the longest (between 19 and 24 months).

d) Time dedicated to play in CityVille. Whereas $18.1 \%$ play less than one hour a day, $30.5 \%$ dedicate between 1 and 2 hours a day; identical percentages correspond to those playing from 3 to 5 hours every day; and a remarkable percentage of $16.2 \%$ claim to play over 5 hours a day. However, $2.9 \%$ of interviewees say that they only play sporadically once a week -together with $1.9 \%$, who does so twice a week.

\footnotetext{
Virtual player profile associated with personal motivation to play in CityVille. M. Esther del Moral Pérez y Alba Patricia Guzmán Duque.

Página 8 de 18
} 
e) Level reached in the game. Figure 2 shows that $43.8 \%$ are above level 100; $29.5 \%$ are situated between levels 51 and 100; 11.4\% have reached the levels comprised between 11 and 20; 9.5\% are located between levels 21 and 50; and another $9.5 \%$ are above level 200 . Only $2.9 \%$ show levels between 6 and 10; those with levels below that (1 to 5) only account for $1.9 \%$.

f) Population of the cities created by players. $18.1 \%$ claim to have between 1,001 and 50,000 inhabitants in their city; $15.2 \%$ between 200,001 and 300,000; 10.5\% between 100,001 and 200,000; and 8.6\% between 600,001 and 700,000; the same percentage (7.6\%) corresponds to players who have from 300,001 to 400,000 inhabitants and those who have from 400,001 to 500,000; those who have between 50,001 and 100,000 inhabitants and those who have less than 1,000 are in the same proportion $(6.7 \%)$ as well; $5.7 \%$ say that they have from 700,001 to 800,000 inhabitants; $4.8 \%$ have between 500,001 and 600,001; and the smallest percentages $(1.0 \%)$ correspond to players who claim to have the largest numbers of virtual inhabitants, namely: between 900,001 and 1,000,000 and above 1,000,000.

Figure 2. Level reached by players belonging to the Fans-CityVille community. Elaborated by the authors

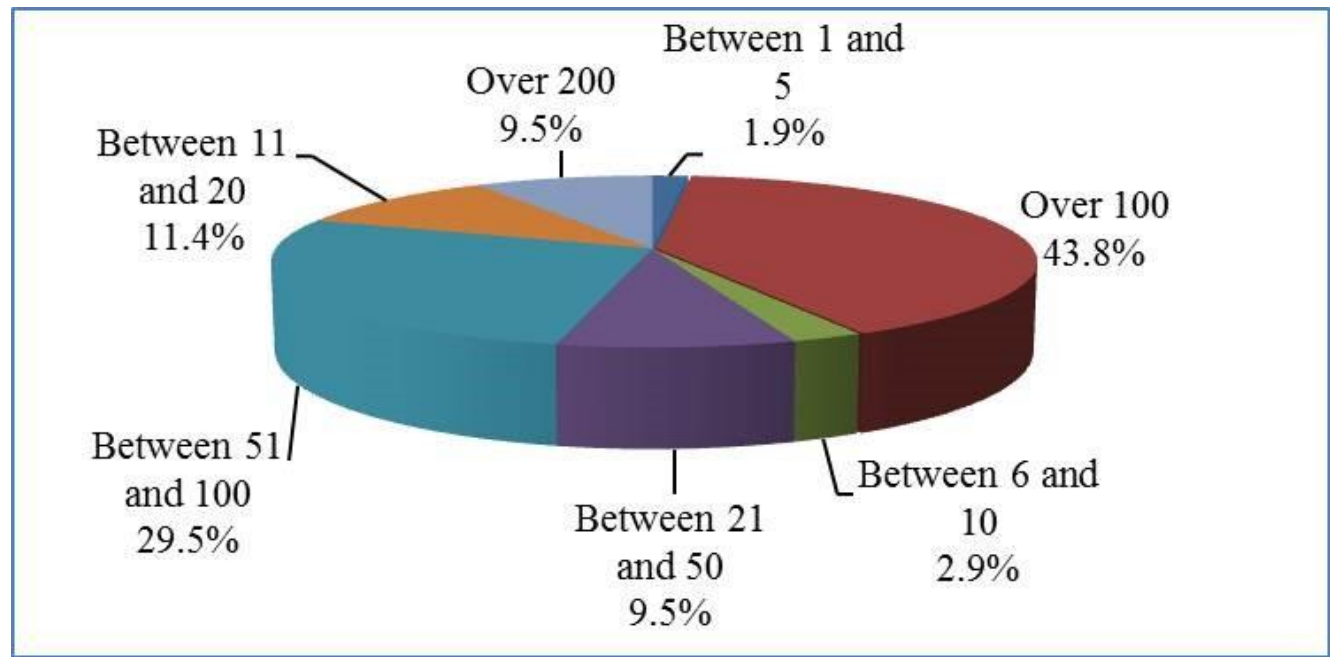

g) Number of neighbors. $27.6 \%$ of players have over 100 neighbors, a mean of 140 $(S D=23.0$; Range situated between 105 and 200 ), followed by $14.4 \%$ who say that they have between 11 and 20 neighbors; 10.5\% have from 1 to 10; 9.5\% claim to have between 31 and 40 neighbors; 8.6\% between 81 and 90; 7.6\%, between 21 and 30; $6.7 \%$ between 91 and 100; 5.7\% between 51 and 60; and an identical percentage $(4.8 \%)$ is shared by players who have from 71 to 80 neighbors and those who have between 41 and 50 .

h) Economic investment. Even though $52.4 \%$ of interviewees say that they do not invest any money in the game, the remaining $47.6 \%$ admit that they have a fixed monthly expense. More precisely, $19.0 \%$ invest between 2.31 and 5.75 USD, followed by $13.3 \%$ who claim to spend from 5.76 to 11.50 USD; $8.6 \%$ invest the minimum established in the game (2.30 USD); and 6.7\% situate their spending between 11.51 and 23.00 USD.

After describing the overall context defined by the sample, the next step consist in examining the reasons and aims adduced by respondents to justify their presence and ludic-communicative activity in CityVille. 


\section{Results}

\section{Reasons to play in CityVille}

Kim, Kim, Shim, Im \& Shon (2013) warn about behaviors suggesting addiction to videogames related to subjects' motivation; for that reason, it was considered relevant to ask CityVille players about the reasons which lead them to spend time playing on a network. This allowed us to verify the relationship between the need to have fun and escape from reality in order to feel happy, the satisfaction with personal achievements within these virtual ludic contexts, and even the conviction of feeling self-fulfilled with the game. This is a relevant fact because, as pointed out by Snodgrass et al. (2012), gamers' motivations shape both positive and negative experiences and, more specifically, social immersion games result in more positive playing experiences if they pursue a constructive aim.

Table 2 shows the distribution of subjects according to the level of agreement with the reasons that push them to play in CityVille. Almost all of them $(96.2 \%)$ say that they quite agree or totally agree that they have fun playing in CityVille, $89.5 \%$ claim to feel happy when they play; and $88.5 \%$ quite agree that they feel satisfied when they play. Greater dispersion is found when analyzing the level of agreement with the statement that they feel self-fulfilled, although answers are situated around I quite agree or I totally agree (54.3\%) and I agree (33.3\%).

Table 2. Subjects' percent distribution according to the reasons which lead them to play in CityVille. Elaborated by the authors

\begin{tabular}{|l|c|c|c|c|c|c|c|c|}
\hline \multirow{2}{*}{$\begin{array}{c}\text { Reasons to play in } \\
\text { CityVille (CV) }\end{array}$} & \multicolumn{2}{|c|}{$\begin{array}{c}\text { I disagree or } \\
\text { hardly agree }\end{array}$} & \multicolumn{2}{|c|}{ I agree } & \multicolumn{2}{c|}{$\begin{array}{c}\text { I quite agree } \\
\text { or totally } \\
\text { agree }\end{array}$} & Mean & $S D$ \\
\cline { 2 - 10 } & $N$ & $\%$ & $N$ & $\%$ & $N$ & $\%$ & \\
\hline $\begin{array}{l}\text { 1. I have fun playing } \\
\text { in CV }\end{array}$ & 2 & 1.9 & 2 & 1.9 & 101 & 96.2 & 4.86 & 0.627 \\
\hline $\begin{array}{l}\text { 2. I feel satisfied } \\
\text { when I play in CV }\end{array}$ & 3 & 2.9 & 9 & 8.6 & 93 & 88.5 & 4.48 & 0.810 \\
\hline $\begin{array}{l}\text { 3. I feel happy when I } \\
\text { play in CV }\end{array}$ & 1 & 1.0 & 10 & 9.5 & 94 & 89.5 & 4.56 & 0.706 \\
\hline $\begin{array}{l}\text { 4. I feel self-fulfilled } \\
\text { when I play in CV }\end{array}$ & 13 & 12.4 & 35 & 33.3 & 57 & 54.3 & 3.48 & 1.119 \\
\hline \multicolumn{7}{|c|}{ N = Sample taken from the Fans-CityVille community (105 subjects) } \\
\hline
\end{tabular}

Correlations show that the number of hours dedicated to play in CityVille every day is positively related to most of their reasons $(\mathrm{W}=.181)$, with the level that they have reached in the game and, consequently, with the number of inhabitants and neighbors that they have $(\mathrm{W}>.203, \mathrm{p}<.015)$. Multiple regression analysis identified the two reasons which influence their economic investment: feeling happy when they play and feeling self-fulfilled $\left(R^{2}=0.240, p<.000\right)$.

The ANOVA served to detect that no significant differences exist between men and women when it comes to the reasons for playing in CityVille. Furthermore, the sex variable has no bearing on men playing more than women $(p<.076)$ depending on their level.

\footnotetext{
Virtual player profile associated with personal motivation to play in CityVille. M. Esther del Moral Pérez y Alba Patricia Guzmán Duque. 


\section{Objectives to play in CityVille}

Players were asked about the purposes guiding their play, and the answers allowed us to see, on the one hand, the most utilitarian and addictive features of those who prioritize the collection of energy to play on, the construction of their dream city and feeling as powerful owners even if it is only in a fictional world; and, on the other hand, those of players who consider the opportunities for learning and strategy exchange, or those who place the emphasis on the possibility of socialization that it entails (Table 3 ).

Table 3. Subjects' percent distribution according to the objectives which they prioritize to play in CityVille. Elaborated by the authors

\begin{tabular}{|c|c|c|c|c|c|c|c|c|}
\hline \multirow{2}{*}{$\begin{array}{l}\text { Objectives to play } \\
\text { in CityVille (CV) }\end{array}$} & \multicolumn{2}{|c|}{$\begin{array}{l}\text { I disagree or } \\
\text { hardly agree }\end{array}$} & \multicolumn{2}{|c|}{ I agree } & \multicolumn{2}{|c|}{$\begin{array}{l}\text { I quite agree } \\
\text { or totally } \\
\text { agree }\end{array}$} & \multirow[t]{2}{*}{ Mean } & \multirow[t]{2}{*}{$S D$} \\
\hline & $N$ & $\%$ & $N$ & $\%$ & $N$ & $\%$ & & \\
\hline 1. Having fun & 1 & 1.0 & 1 & 1.0 & 103 & 98.0 & 4.90 & 0.471 \\
\hline 2. Interacting & 1 & 1.0 & 6 & 5.7 & 98 & 93.3 & 4.63 & 0.683 \\
\hline $\begin{array}{l}\text { 3. Meeting new } \\
\text { people }\end{array}$ & 2 & 1.9 & 9 & 8.6 & 94 & 89.5 & 4.54 & 0.772 \\
\hline $\begin{array}{l}\text { 4. Staying in touch } \\
\text { with friends }\end{array}$ & 2 & 1.9 & 7 & 6.7 & 96 & 91.4 & 4.61 & 0.740 \\
\hline $\begin{array}{l}\text { 5. Sharing my hobby } \\
\text { with others }\end{array}$ & 2 & 1.9 & 7 & 6.7 & 96 & 91.4 & 4.61 & 0.778 \\
\hline $\begin{array}{l}\text { 6. Constructing my } \\
\text { dream city }\end{array}$ & 3 & 2.9 & 76 & 5.7 & 96 & 91.4 & 4.68 & 0.714 \\
\hline $\begin{array}{l}\text { 7. Owning something } \\
\text { even if it is virtual }\end{array}$ & 3 & 2.9 & 4 & 3.8 & 98 & 93.3 & 4.70 & 0.681 \\
\hline $\begin{array}{l}\text { 8. Learning new } \\
\text { strategies }\end{array}$ & 2 & 1.9 & 7 & 6.7 & 96 & 91.4 & 4.65 & 0.693 \\
\hline 9. Sharing strategies & 3 & 2.9 & 7 & 6.7 & 95 & 90.4 & 4.55 & 0.784 \\
\hline $\begin{array}{l}\text { 10. Obtaining energy } \\
\text { to play on }\end{array}$ & 2 & 1.9 & 5 & 4.8 & 98 & 93.3 & 4.70 & 0.692 \\
\hline
\end{tabular}

Nearly all our interviewees $(98.0 \%)$ state that they play to have fun; the addictive nuance reveals itself through other statements since, in turn, $93.3 \%$ claim to do so with the aim of obtaining energy, interacting, and owning something even if it is virtual. Another $91.4 \%$ link their play to the possibility of constructing their dream city, sharing their hobby with others, learning new strategies and contacting with other players. And $89.5 \%$ relate it to the opportunity that the game gives them to meet people.

Correlations confirm that the number of hours dedicated to the game is positively related to most of the objectives that players prioritize in CityVille, with the level that they have reached in the game, and with the number of neighbors $(\mathrm{W}>.213, \mathrm{p}<.015)$. Multiple regression analysis shows that, although all the objectives positively and significantly correlate with the variable money invested in the game $\left(R^{2}=0.135, p<\right.$ .000 ), it can be seen that the main objective sought by players when they invest money in CityVille is progressing faster within levels $\left(R^{2}=0.107, p<.001\right)$. It was additionally

Virtual player profile associated with personal motivation to play in CityVille. M. Esther del Moral Pérez y Alba Patricia Guzmán Duque. 
detected that the users who spend the most money play more hours too; and, therefore, they reach higher levels $\left(R^{2}=0.352, p<.000\right)$. Instead, those who do not invest money dedicate less time to the game: $32.7 \%$ between 1 and 2 hours a day; $30.9 \%$ have a population situated between 1,001 and 50,000 inhabitants; $25.5 \%$ have between 11 and 20 neighbors; 20.0\% have between 31 and 40 neighbors; and $36.4 \%$ are situated on levels ranging from 51 to $100 ; 21.8 \%$ from 11 to 20; and 18.2\% from 21 to 50. Carrying out the multiple regression analysis allowed us to see that the money invested in the game is related to the sex variable $(p<.000)$, women being the ones who invest more money $(p<.027)$.

The ANOVA revealed the existence of significant differences between the aims that women and men set themselves in the game; while women prefer to share strategies $(p<.009)$, men prefer to obtain more XP to move up levels $(p<.068)$.

\section{Priorities to communicate with their neighbors in CityVille}

Networked play adds a distinctive component to conventional videogames, insofar as it provides a variety of formulas and tools which make communication between users easier. CityVille even fosters communication with rewards and the acquisition of resources to continue playing and to reach higher levels of power. Nevertheless, it is the individual factor that determines the relationships between subjects; hence our decision to ask our interviewees to express their priorities when it came to communicating with their play partners (Table 4).

Table 4. Subjects' percent distribution according to their priorities to communicate with their neighbors in CityVille. Elaborated by the authors

\begin{tabular}{|l|c|c|c|c|c|c|c|c|}
\hline \multirow{2}{*}{$\begin{array}{l}\text { Prioritize to play in } \\
\text { CityVille (CV) }\end{array}$} & \multicolumn{2}{|c|}{$\begin{array}{l}\text { I disagree or } \\
\text { hardly agree }\end{array}$} & \multicolumn{2}{|c|}{ I agree } & \multicolumn{2}{|c|}{$\begin{array}{c}\text { I quite agree } \\
\text { or totally } \\
\text { agree }\end{array}$} & \multirow{2}{*}{ Mean } & $S D$ \\
\cline { 2 - 10 } & $N$ & $\%$ & $N$ & $\%$ & $N$ & $\%$ & & \\
\hline 1. Expanding my city & 2 & 1.9 & 4 & 3.8 & 99 & 94.3 & 4.74 & 0.707 \\
\hline $\begin{array}{l}\text { 2. Helping them } \\
\text { expand their city }\end{array}$ & 3 & 2.9 & 7 & 6.7 & 95 & 90.4 & 4.53 & 0.821 \\
\hline $\begin{array}{l}\text { 3. Asking them for } \\
\text { help }\end{array}$ & 1 & 1.0 & 7 & 6.7 & 97 & 92.3 & 4.64 & 0.735 \\
\hline 4. Sharing strategies & 4 & 3.8 & 11 & 10.5 & 90 & 85.7 & 4.47 & 0.899 \\
\hline $\begin{array}{l}\text { 5. Collecting energy } \\
\text { to play on }\end{array}$ & 1 & 1.0 & 8 & 7.6 & 96 & 91.4 & 4.66 & 0.705 \\
\hline $\begin{array}{l}\text { 6. Obtaining more XP } \\
\text { to go up levels }\end{array}$ & 2 & 1.9 & 8 & 7.6 & 95 & 90.5 & 4.64 & 0.748 \\
\hline $\begin{array}{l}\text { 7. Collaborating by } \\
\text { offering them gifts }\end{array}$ & 6 & 5.7 & 12 & 11.4 & 87 & 82.9 & 4.42 & 0.998 \\
\hline $\begin{array}{l}\text { 8. Obtaining items to } \\
\text { build }\end{array}$ & 5 & 4.7 & 7 & 6.7 & 93 & 88.6 & 4.55 & 0.920 \\
\hline $\begin{array}{l}\text { 9. Progressing faster } \\
\text { within levels }\end{array}$ & 4 & 3.8 & 5 & 4.8 & 96 & 91.4 & 4.67 & 0.816 \\
\hline \multicolumn{7}{|c|}{$\mathrm{N}=$ Sample taken from the Fans-CityVille community (105 subjects) } \\
\hline
\end{tabular}

$\overline{\text { Virtual player profile associated with personal motivation to play in CityVille. M. Esther del Moral Pérez }}$ y Alba Patricia Guzmán Duque. 
A very high proportion of respondents quite agree or totally agree (94.3\%) that one of the priorities when it comes to communicating with their neighbors is expanding their own city -an attitude which is rewarded by the game- and that is the reason adduced by $91.4 \%$, who add that it allows them to progress faster and to obtain energy to play on; followed by $90.5 \%$ who justify their approach to communication because it helps them expand their city and to collect more XP to move up levels. These clearly competitive approaches are reinforced by the game and they can even be categorized as somewhat utilitarian because interdependence relationships determined by individual interests are generated as a result. Something that also deserves to be highlighted when analyzing our interviewees' answers is the percentage corresponding to players for whom the priority lies in asking them for help (92.3\%) or items to build (88.6\%), compared to those who communicate with the aim of helping other people expand their city or offering them gifts (82.9\%).

It additionally becomes evident that the game favors different types of implicit learning which users gradually incorporate into their playing experience, adopting various strategies to optimize the process of construction and expansion of their own city. In this respect, it can be observed that $85.7 \%$ express their total agreement, saying that they communicate with their neighbors for the purpose of sharing strategies.

Correlations help us detect that the number of hours dedicated to the game every day are positively related not only to players' priorities, to the level they have reached, and to the number of neighbors and inhabitants that they have $(\mathrm{W}>.177)$ but also, logically, to their condition as regular players, to how long they have been playing the game and to the money that they invest every month $(\mathrm{W}=.226)$. Therefore, the higher the investment made, the higher level is reached in the game and the higher number of inhabitants is achieved $(\mathrm{W}>.545 ; \mathrm{p}<.000)$.

Multiple regression analysis revealed that the sex variable is related to the number of neighbors in their cities and, naturally to game level $\left(R^{2}=0.335, p<.013\right)$, men being the ones who have more neighbors and consequently reach higher levels in CityVille.

When an attempt was made to check whether or not significant differences existed between the priorities established by men and women when it comes to communicating with other players, the ANOVA showed that women primarily communicate with their neighbors in order to help them expand their city and to share strategies $(p<.040)$, whereas men communicate with others because it provides them with a guarantee that they will be able to build their dream city, to own something even if it is virtual and to learn new strategies $(\mathrm{p}<.000)$.

\section{Discussion}

The descriptive statistical data reveal that the members of Fans-CityVille community follow a pattern: although both men and women play, male players $(62.9 \%)$ outnumber female players $(37.1 \%)$. They are all grouped together around the higher-level Italian player, and their neighbors thus include fellow countrymen users, friends of their friends' and Colombian players can be found in similar proportions, together with their neighbors who answered the questionnaire and, consequently, with their circle of friends.

$44.8 \%$ of players are 40 years old on average. $51.4 \%$ are registered on at least 3 games on social networks, and $44.8 \%$ have been playing for about 15 months. $30.5 \%$ play between 1 and 2 hours a day, followed by a considerable group (18.1\%) who dedicate from 3 to 5 hours to the game. $43.8 \%$ reach levels close to $100.18 .1 \%$ have populations between 1,001 and 50,000, followed by $15.2 \%$ who have from 200,001 to 300,000 inhabitants. As for neighbors, $27.6 \%$ have over 100 neighbors. $47.6 \%$ of players spend 8 USD every month on average, whereas $19.0 \%$ invest the minimum established in the game (between 2.30 and 5.75 USD).

Virtual player profile associated with personal motivation to play in CityVille. M. Esther del Moral Pérez y Alba Patricia Guzmán Duque.

Página 13 de 18 
Correlations indicate that the reasons leading our respondents to play in CityVille having fun, feeling happy and self-fulfilled with the game- have a positive impact on their efforts to achieve more neighbors and inhabitants in their cities and, therefore, on their chances to reach higher levels. These assets provide them with an assurance of faster progress in the game. The same happens with their objectives, insofar as their determination to reach them -having fun, owning something even if it is virtual, interacting with others, expanding their city...- affects their access to higher levels, while this at the same time significantly correlates with their priority reasons that they claim to have established to communicate with their neighbors.

The players who invest the most money in CityVille are the ones who dedicate more time to the game and who, logically, reach the highest levels -women being the ones who spend the most money $(\mathrm{p}<.027)$. It can be stated that those who play more also spend more $\left(\mathbf{R}^{2}=0.352\right)$. The economic investment ensures a rapid access to higher levels, achieving more inhabitants in their virtual cities, more neighbors, etc., something which undoubtedly benefits the search not only for their self-satisfaction but also for the social recognition that it brings them among their friends and neighbors or players belonging to their virtual socialization network.

In addition to having fun, players also see CityVille as a way to develop their creativity from the expansion of their city; they request their neighbors' support through the interaction and communication made easier and rewarded with energy or additional points to progress quickly and build a megacity. In this regard, it is verified that the game contributes to facilitate collaboration, strategy exchange, as stated by $85.7 \%$ of interviewees, who communicate with their neighbors for the purpose of sharing strategies especially oriented to expand their virtual city more rapidly.

CityVille encourages interaction and communication among its users by means of specific rules. The visits to neighbors suggested by the game facilitate the growth of virtual cities as well as faster progress thanks to the positive reinforcements that these visits receive.

Significant differences were identified both in the respective objectives that men and women set themselves in CityVille and in the priorities that they establish to communicate with other players. Women prefer to share strategies, while men seek to obtain more XP in order to go up levels; this allows them to reach the highest levels. Finally, unlike women, who prioritize communication with their neighbors in order to help them expand their city and share strategies, men communicate with their neighbors because doing it assures them that they will be able to build their dream city, to own something even if it is virtual and to learn new strategies.

\section{Conclusions}

Taking advantage of the connectivity offered by social networks, some online games promote users' participation and interaction with their community, thus turning the game not only into an instrument for entertainment but also into a mechanism to help players communicate and interact with one another. Although some war games bring together a very large number of players, the present research sought to analyze the extent to which prosocial games such as CityVille find support on the social interactions generated on networks in order to favor collaborative construction as well as the development of interpersonal skills.

CityVille gives the chance to build a city and promotes collaborative communication between its players, encouraging and rewarding their mutual interaction where, despite the key role which corresponds to planning as well as to the implementation of effective strategies to expand their virtual cities, the help offered by neighbors makes it possible to progress in the game, achieving greater accomplishments and levels of power. Its design and play mechanics guarantee the effect of immersion for players, contributing

Virtual player profile associated with personal motivation to play in CityVille. M. Esther del Moral Pérez y Alba Patricia Guzmán Duque.

Página 14 de 18 
to a gradual progress through levels by means of the constant rewards delivered which, together with the fulfillment of accessible aims -and at the pace that players set themselves- make it become an attractive ludic environment which permits collaborative interaction with others, promoting healthy leisure spaces and seeking one's own growth without the need to appeal to war practices.

The reasons why users play in CityVille have to do with the wish to feel happy and satisfied, they have fun making their city grow through the display of all their creativity and owning something even if it is virtual. Likewise, the goals that players set themselves are oriented both to win, to reach the different levels, to collect energy to build their dream city and to feel as owners and implicitly -through the visits to their neighbors- to learn new strategies that can help expand their cities and increase their mutual socialization levels. Without a doubt these types of games on social networks favor a flexible type of communication between users and promote what has come to be known as prosocial entertainment.

Although the priorities established by players when it comes to communicating with their neighbors respond have to do with unmistakably competitive interests such as expanding their own city, the game contributes to facilitate collaboration and strategy exchange, insofar as players are not only encouraged to interact with their neighbors either to ask them for help or to offer them their help, but also the game rewards that sort of behavior, favoring a more rapid growth of cities and offering players advantages in return for their mutual collaboration such as, for instance, progressing faster within levels and collecting XP energy to reach the next level.

The interaction promoted by CityVille additionally enables them to learn from the design and organizational strategies utilized by other players. The evolution of cities makes it possible to see the mimesis effect derived from the visits to their neighbors, the exchange of experiences and the transfer of learning from the most prestigious players' best practices such as the effective organization of the city's basic infrastructures, the appropriate distribution of spaces and services to maintain its inhabitants' quality of life, the rational exploitation of natural resources to guarantee urban supply, etc.

The significant differences between female and male players stress women's social motivation to share strategies with their play neighbors, and men's more competitive character, as the latter focus all their efforts preferably on the growth of their cities in an interactive and non-war-related fashion.

It can finally be inferred that a reasonable, non-addictive dedication to the game CityVille offers its players opportunities which go beyond mere entertainment, since it permits the development of prosocial strategies and interpersonal skills. This is so because players can only move up levels if they combine several alternatives; it promotes collaborative work from a constructive approach, generating interdependence relationships with neighbors, insofar as they need the collaboration of those neighbors in order to expand their city; and it boosts interaction and communication, favoring and further consolidating the relationships with their virtual friends and/or neighbors, and broadening their social networks from the game, understood as the pursuit of a common interest: the construction of ideal cities in this case.

Presentación del artículo: 13 de febrero de 2017 Fecha de aprobación: 15 de marzo de 2017 Fecha de publicación: 30 de junio de 2017

Virtual player profile associated with personal motivation to play in CityVille. M. Esther del Moral Pérez y Alba Patricia Guzmán Duque. 
Del Moral Pérez, M.E., y Guzmán Duque, A.P. (2017). Virtual player profile associated with personal motivation to play in CityVille. RED. Revista de Educación a Distancia, 54. Consultado el (dd/mm/aaaa) en http://www.um.es/ead/red/54/

\section{FINANCIACIÓN}

El presente trabajo se inserta en el proyecto de investigación denominado E3M "European Indicator and Ranking Methodology for University Third Mission", en el Centro de Gestión de la Calidad y del Cambio de la Universitat Politècnica de València (UPV).

\section{FUNDING}

This paper is included within the research project titled "European Indicator and Ranking Methodology for University Third Mission", recognized by Centro de Gestión de la Calidad y del Cambio de la Universitat Politècnica de València (UPV).

\section{REFERENCES}

Burroughs, B. (2014). Facebook and FarmVille A Digital Ritual Analysis of Social Gaming. Games and Culture, 9(3), 151-166. Doi: 10.1177/1555412014535663

Camilleri, V., Busuttil, L., \& Montebello, M. (2011). Social Interactive Learning in Multiplayer Games. In: Ma, M., Oikonomou, A., Jain, L.C. (eds.). Serious Games and Edutainment Applications. London: Springer-Verlag.

Caplan, S., Williams, D., \& Yee, N. (2009). Problematic Internet use and psychosocial well-being among MMO players. Computers in Human Behavior, 25(6), 13121319. Doi: 10.1016/j.chb.2009.06.006

Carnagey, N.L., Anderson, C.A., \& Bushman, B.J. (2007). The Effect of Videogame Violence on Physiological Desensitization to Real-World Violence. Journal of Experimental Social Psychology, 43, 489-496. Doi: 10.1016/j.jesp.2006.05.003

Chiang, Y. T., Lin, S. S., Cheng, C. Y., \& Liu, E. Z. F. (2011). Exploring Online Game Players' Flow Experiences and Positive Affect. Turkish Online Journal of Educational Technology-TOJET, 10(1), 106-114.

Choi, H., Choi, E., \& Song, S. (2012). The structure of affection descriptors for social network game: case study of CityVille on Facebook. Multimedia Tools and Applications, 68(2), 375-389. Doi: 10.1007/s11042-012-1310-y

Cole, H., \& Griffiths, M.D. (2007). Social interactions in massively multiplayer online role-playing gamers. Cyberpsychology \& Behavior, 10(4), 575-583. Doi: 10.1089/cpb.2007.9988

Connolly, T.M., Boyle, E.A, MacArthur, E., Hainey, T., \& Boyle, J. (2012). A systematic literature review of empirical evidence on computer games and serious games. Computers \& Education, 59(2), 661-686. Doi: 10.1016/j.compedu.2012.03.004

Corliss, J. (2011). Introduction: The Social Science Study of Video Games. Games \& Culture, 6(1), 3-16. Doi: 10.1177/1555412010377323

Cowley, B., Charles, D., Black, M., \& Hickey, R. (2008). Toward an understanding of flow in video games. Computers in Entertainment, 6(2), 1-27. Doi: 10.1145/1371216.1371223

De Andrade, S. (June, 2012). Buy and Share! Social Network Games and Ludic Shopping. DiGRA Nordic 2012 Conference: Local and Global-Games in Culture and Society, vol. 10. Tampere, Finland.

\footnotetext{
Virtual player profile associated with personal motivation to play in CityVille. M. Esther del Moral Pérez y Alba Patricia Guzmán Duque. 
Delisi, M., Vaughn, M.G., Gentile, D.A., Anderson, C.A., \& Shook, J.J. (2013). Violent Video Games, Delinquency and Youth Violence: New Evidence. Youth Violence and Juvenile Justice, 11(2), 132-142, Doi: 10.1177/1541204012460874

Desurvire, H., \& Wiberg, C. (2009). Game Usability Heuristics (PLAY) for Evaluating and Designing Better Games: The Next Iteration. In: Ozok, A. Ant; Zaphiris, Panayiotis (eds.). Proceedings of the $3 d$ International Conference on Online Communities and Social Computing: Held as Part of HCl International (pp. 557566). Berlin: Springer-Verlag.

De Vane, B., \& Squire, K.D. (2008). The Meaning of Race and Violence in Grand Theft Auto San Andreas. Games and Culture, 3(3-4), 264-285. Doi: $10.1177 / 1555412008317308$

Ducheneaut, N., \& Moore, R. J. (2005). More than just "XP": Learning social skills in massively multiplayer online games. Interactive Technology and Smart Education, 2, 89-100.

Ducheneaut, N., Yee, N., Nickell, E., \& Moore, R. J. (2006). Building an MMO with mass appeal a look at gameplay in world of warcraft. Games and Culture, 1(4), 281-317. Doi: 10.1177/1555412006292613

Ducheneaut, N., Moore, R.J., \& Nickell, E. (2007). Virtual third places: A case study of sociability in massively multiplayer games. Computer Supported Cooperative Work, 16(1-2), 129-166. Doi: 10.1007/s10606-007-9041-8

Feinleib, D. (2011). Why Startups Fail: And How Yours Can Succeed. London: Apress.

Gagnon, F. (2010). Invading Your Hearts and Minds: Call of Duty® and the (Re)Writing of Militarism in US Digital Games and Popular Culture. European Journal of American Studies, 5(3), 1-17.

Granic, I., Lobel, A., \& Engels, R.C. (2013). The Benefits of Playing Video Games. American Psychological Association, 69(1), 66-78. Doi: 10.1037/a0034857

Greitemeyer, T., \& Osswald, S. (2010). Effects of prosocial video games on prosocial behavior. Journal of Personality \& Social Psychology, 98(2), 211-221.

Hair, J.F., Tatham, R. L., Anderson, R. E., \& Black, W. (2010). Análisis multivariante. Madrid: Prentice Hall.

Hou, H.T. (2012). Exploring the behavioral patterns of learners in an educational massively multiple online role-playing game (MMORPG). Computers \& Education, 58(4), 1225-1233. Doi: 10.1016/j.compedu.2011.11.015

Hussain, Z., \& Griffiths, M.D. (2009). The Attitudes, Feelings, and Experiences of Online Gamers: A Qualitative Analysis. CyberPsychology \& Behavior, 12(6), 747-753. Doi: 10.1089/cpb.2009.0059

Jeon, G. (2001). A study on the structure and characteristics of social games. Journal of Korea Game Society, 11(6), 13-22.

Jørgersen, K. (2012). Between the Game System and the Fictional World: A Study of Computer Game Interfaces. Games and Culture, 7(2), 142-163. Doi: 10.1177/1555412012440315

Kim, E.J., Namkoong, K., Ku, T., \& Kim, S. J. (2008). The relationship between online game addiction and aggression, self-control and narcissistic personality traits. European Psychiatry, 23(3), 212-218. Doi: 10.1016/j.eurpsy.2007.10.010

Kim, P.W., Kim, S.Y., Shim, M., Im, C.H., \& Shon, Y. M. (2013). The influence of an educational course on language expression and treatment of gaming addiction for massive multiplayer online role-playing game (MMORPG) players. Computers \& Education, 63, 208-217. Doi: 10.1016/j.compedu.2012.12.008

Kindaid, J. (2010). First Look: Zynga Takes On Rivals With CityVille, A Casual Virtual Metropolis. Techcrunch.com, 2010.

Kowert, R., \& Oldmeadow, J.A. (2013). (A)Social reputation: Exploring the relationship between online video game involvement and social competence. Computers in Human Behavior, 29(4), 1872-1878. Doi: 10.1016/j.chb.2013.03.003 
Liu, M., \& Peng, W. (2009). Cognitive and psychological predictors of the negative outcomes associated with playing MMOGs (Massively Multiplayer Online Games). Computers in Human Behavior, 25(6), 1306-1311. Doi: 10.1016/j.chb.2009.06.002

Lo, S.K., Wang, C.C., \& Fang, W. (2005). Physical interpersonal relationships and social anxiety among online game players. CyberPsychology \& Behavior, 8(1), 15-20. Doi: $10.1089 / \mathrm{cpb} .2005 .8 .15$

Nummenmaa, T., Alha, K., \& Kultima, A. (2011). Towards Game Evolution Planning Through Simulation. En: Kultima, A.; Peltoniemi, M. (eds). Games and Innovation Research Seminar 2011 Working Papers. TRIM Research Reports 7. Tampere, Finland: School of Information Sciences, University of Tampere.

Paraskeva, F., Mysirlaki, S., \& Papagianni, A. (2010). Multiplayer online games as educational tools: Facing new challenges in learning. Computers \& Education, 54(2), 498-505. Doi: 10.1016/j.compedu.2009.09.001

Shaw, A. (2010). What Is Video Game Culture? Cultural Studies and Game Studies. Games and Culture, 5(4), 403-424.

Siemens, G. (2008). Collective or connective intelligence. In: Connectivism blog, 2008.

Smith, S.L., \& Moyer-Gusé, E. (2005). Voluptuous Vixens and Macho Males: A Look at the Portrayal of Gender and Sexuality in Video Games. Reichert, T. \& Lambiase, J. (eds). Sex in Consumer Culture. The Erotic Content of Media and Marketing. USA: Routledge.

Snodgrass, J.G., Dengah, H.F., Lacy, M.G., Fagan, J., Most, D., ... \& Wintersteen, B. (2012). Restorative magical adventure or warcrack? Motivated MMO play and the pleasures and perils of online experience. Games and Culture, 7(1), 3-28. Doi: $10.1177 / 1555412012440312$

Taylor, T.L. (2009). The Assemblage of Play. Games and Culture, 4(4), 331-339. Doi: $10.1177 / 1555412009343576$

Tear, M.J., \& Nielsen, M. (2013). Failure to Demonstrate That Playing Violent Video Games Diminishes Prosocial Behavior. PLOS ONE, 8(7), 368-382. Doi: 10.1371/journal.pone.0068382

Van Meurs, R. (2011). And Then You Wait: The Issue of Dead Time in Social Network Games. DiGRA 2011 Conference: Think Design Play. Tampere, Finland.

Wang, C.S., \& Chiou, W.B. (2006). Psychological Motives and Online Games Addiction: A Test of Flow Theory and Humanistic Needs Theory for Taiwanese Adolescents. CyberPsychology \& Behavior, 9(3), 317-324. Doi: 10.1089/cpb.2006.9.317

Weibel, D., Wissmath, B., Habegger, S., Steiner, Y., \& Groner, R. (2008). Playing online games against computer-vs. human-controlled opponents: Effects on presence, flow, and enjoyment. Computers in Human Behavior, 24(5), 22742291. Doi: 10.1016/j.chb.2007.11.002

Whitaker, J.L., \& Bushman, B.J. (2012). "Boom, Headshot!": Effect of Video Game Play and Controller Type on Firing Aim and Accuracy. Communication Research, 41(7), 879-891, Doi: 10.1177/0093650212446622

Williams, D., Kennedy, T., \& Moore, R.J. (2011). Behind the avatar: The patterns, practices, and functions of roleplaying in MMOs. Games and Culture, 6(2), 171200. Doi: $10.1177 / 1555412010364983$

Wohn, D. Y., Lampe, C., Wash, R., Ellison, N., \& Vitak, J. (2011). The "S" in Social Network Games: Initiating, Maintaining, and Enhancing Relationships. The 44th Hawaii International Conference on System Sciences, Hawaii, USA.

Zynga (2013). Información corporativa de Zynga. In http://zynga.com/

Virtual player profile associated with personal motivation to play in CityVille. M. Esther del Moral Pérez y Alba Patricia Guzmán Duque. 